\title{
Mechanistic Studies of Pd-Catalyzed Fluorination of Cyclic Vinyl Triflates: Evidence for in situ Ligand Modification
}

Yuxuan Ye, ${ }^{\dagger}, \|$ Seoung-Tae Kim, $,{ }^{\ddagger}, \|$, Ryan P. King, ${ }^{\dagger}$ Mu-Hyun Baik, ${ }^{\S, * * *}$ Stephen L. Buchwald ${ }^{\dagger}, *$

'Department of Chemistry, Massachusetts Institute of Technology, Cambridge, MA 02139, USA

"Department of Chemistry, Korea Advanced Institute of Science and Technology (KAIST), Daejeon, 34141, Republic of Korea

${ }^{\S}$ Center for Catalytic Hydrocarbon Functionalizations, Institute for Basic Science (IBS), Daejeon, 34141, Republic of Korea

Pd-catalyzed nucleophilic fluorination reactions are important methods for the synthesis of fluoroarenes and fluoroalkenes. However, these reactions can generate a mixture of regioisomeric products that are often difficult to separate. While investigating the Pdcatalyzed fluorination of cyclic vinyl triflates, we observed that the addition of a substoichiometric quantity of $\mathrm{TESCF}_{3}$ significantly improves both the efficiency and the regioselectivity of the fluorination process. Herein, we report a combined experimental and computational study on the mechanism of this transformation focused on the role of $\mathrm{TESCF}_{3}$. We found that in the absence of additives such as $\mathrm{TESCF}_{3}$, the transmetalation step produces predominantly the thermodynamically more stable trans isomer of the key LPd(vinyl)F complex ( $L=$ biaryl monophosphine ligand). This intermediate, rather than undergoing reductive elimination, preferentially reacts through an intramolecular $\beta$-deprotonation to form a Pd-cyclohexyne intermediate. This undesired reactivity is responsible for the low efficiency (11\% yield) and poor regioselectivity (1.8:1) of the catalytic reaction. When $\mathrm{TESCF}_{3}$ is added to the reaction mixture, the cis-LPd(vinyl)F complex is instead formed, through a pathway involving an unusual dearomatization of the ligand by nucleophilic attack from a trifluoromethyl anion $\left(\mathrm{CF}_{3}{ }^{-}\right)$. In contrast to the trans isomer, this cis-LPd(vinyl)F complex readily undergoes reductive elimination to provide the vinyl fluoride product with desired regioselectivity, without the generation of Pd-cyclohexyne intermediates. 


\section{Introduction}

Fluorine-containing molecules ${ }^{1}$ are a valuable class of compounds with wide applications $^{2,3}$ and desirable biological properties. ${ }^{4} \mathrm{Pd}^{0 / I I}$-catalyzed $\mathrm{C}-\mathrm{F}$ cross-coupling is an attractive approach for the preparation of fluorinated compounds from readily available starting materials. ${ }^{5,6}$ Due to the challenging $\mathrm{C}-\mathrm{F}$ reductive elimination from a $\mathrm{Pd}(\mathrm{II})$ intermediate, ${ }^{7}$ this transformation was not realized until recently. ${ }^{8}$

The generation of undesired regioisomeric fluorinated side products is a significant obstacle affecting $\mathrm{Pd}^{0 / I}$-catalyzed fluorination reactions. ${ }^{8 b, 9 c}$ Previous mechanistic studies on the fluorination of aryl triflates indicated that the Pd-benzyne intermediates, generated from a baseinduced elimination pathway, are responsible for producing undesired regioisomers. ${ }^{9 \mathrm{c}}$ In certain cases, nonpolar solvents such as cyclohexane could be used instead of polar solvents to minimize this undesired process. ${ }^{8 \mathrm{a}, 8 \mathrm{~d}}$ In addition, catalysts based on new ligands were developed, which promoted the aromatic fluorination reaction with higher degrees of regioselectivity and reactivity. ${ }^{8 \mathrm{~d}, 8 \mathrm{e}}$

In 2016, motivated by the utility of fluorine-substituted olefins as amide surrogates in medicinal chemistry and chemical biology, ${ }^{10,11}$ we developed a $\mathrm{Pd}^{0 / I I}$-catalyzed fluorination of cyclic vinyl triflates. ${ }^{12}$ The addition of $\mathrm{TESCF}_{3}$ to the reaction mixture was found to significantly improve both the yield and regioselectivity of the fluorination process. Under the standard reaction conditions using $30 \mathrm{~mol}_{0} \mathrm{TESCF}_{3}$ as the additive, the desired fluorinated product $\mathbf{A}$ was generated in high yield with excellent regioselectivity (Scheme 1, with $\mathrm{TESCF}_{3}, 74 \%$ yield, $\mathbf{A}: \mathbf{B}>$ 99:1). However, in the absence of $\mathrm{TESCF}_{3}$, the same reaction provided the fluorinated products in low yield and poor regioselectivity (Scheme 1, without $\mathrm{TESCF}_{3}, 11 \%$ combined yield, $\mathbf{A}: \mathbf{B}=1.8: 1$ ).

\section{Scheme 1. Pd-Catalyzed Fluorination of Cyclic Vinyl Triflates.}

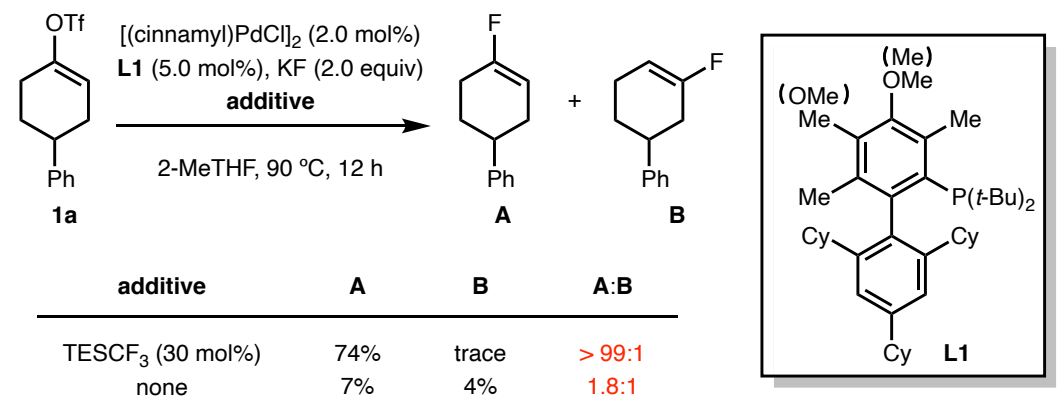

A better understanding of the "TESCF 3 effect" in this fluorination process could provide insight into the mechanism of the fluorination reactions in general and also potentially allow us to expand this strategy to other Pd-catalyzed fluorination systems. Therefore, we undertook a 
combined experimental and computational study on the fluorination of cyclic vinyl triflates, comparing the mechanisms of reaction with and without $\mathrm{TESCF}_{3}$ as an additive. During our study, we uncovered a hitherto unrecognized transmetalation mechanism with fluoride involving an unusual dearomatization of the ligand by nucleophilic attack by a $\mathrm{CF}_{3}{ }^{-}$nucleophile.

\section{Results and Discussion}

\section{Kinetic Profiles of the Fluorination Reaction with and without $\mathrm{TESCF}_{3}$ Additive}

We commenced our investigation by monitoring the progress of a model reaction with and without $\mathrm{TESCF}_{3}$ using ${ }^{19} \mathrm{~F}$ NMR analysis. In the absence of $\mathrm{TESCF}_{3}$, after $5 \mathrm{~h}$, a mixture of isomeric products was formed in $c a$. 10\% combined yield with poor selectivity (Figure 1, without $\mathrm{TESCF}_{3}$ ). In a separate reaction in which $30 \mathrm{~mol}_{0} \mathrm{TESCF}_{3}$ was used as an additive, in the initial stage of the reaction $(\mathrm{t}=0-120 \mathrm{~min})$, no vinyl fluoride products were formed. During this time, $\mathrm{TESCF}_{3}$ was continually consumed, and approximately $15 \%$ of $\mathbf{1 a}$ decomposed via an unknown pathway. Then, after the $\mathrm{TESCF}_{3}$ was fully consumed, the fluorination proceeded smoothly providing the desired vinyl fluoride product $\mathbf{A}$ in good yield (70\% yield in $4 \mathrm{~h}$ ) and with excellent regioselectivity (Figure 1, with $\mathrm{TESCF}_{3}$ ). Compared to the kinetic profile without $\mathrm{TESCF}_{3}$, the addition of a substoichiometric amount of $\mathrm{TESCF}_{3}$ had a dramatic impact on the reaction in several ways. First, the rate of the fluorination process was increased and the regioselectivity was significantly improved. We hypothesized that a new catalytic species with better fluorinating activity might be forming in the presence of $\mathrm{TESCF}_{3}$. Second, an induction period was observed at the beginning of the reaction, during which time no fluorinated product was formed. We reasoned that the presence of $\mathrm{TESCF}_{3}$ inhibited the fluorination process, because fluoride anions would react preferentially with $\mathrm{TESCF}_{3}$, preventing the generation of any $\mathrm{Pd}-\mathrm{F}$ species that is required for product formation. ${ }^{13}$ It was probable that of the $30 \mathrm{~mol}_{0} \mathrm{TESCF}_{3}$ added at the beginning of the reaction, only a small amount participated in the formation of the active catalyst

species, while the rest decomposed to either $\mathrm{CHCF}_{3}$ or $\mathrm{CF}_{2} \mathrm{CF}_{2}$ (observed by ${ }^{19} \mathrm{~F} \mathrm{NMR}$ analysis of the crude reaction mixture) under the reaction conditions. We found that approximately $30 \mathrm{~mol} \%$ was the minimal amount of $\mathrm{TESCF}_{3}$ required to achieve the optimal regiochemical ratio of products (see the Supporting Information for details). 
Figure 1. Reaction Kinetic Profiles with and without $\mathrm{TESCF}_{3}$ as an Additive. ${ }^{\mathrm{a}}$

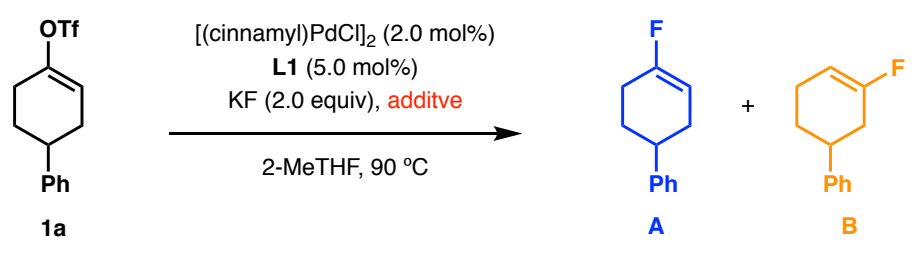

without $\mathrm{TESCF}_{3}$ :

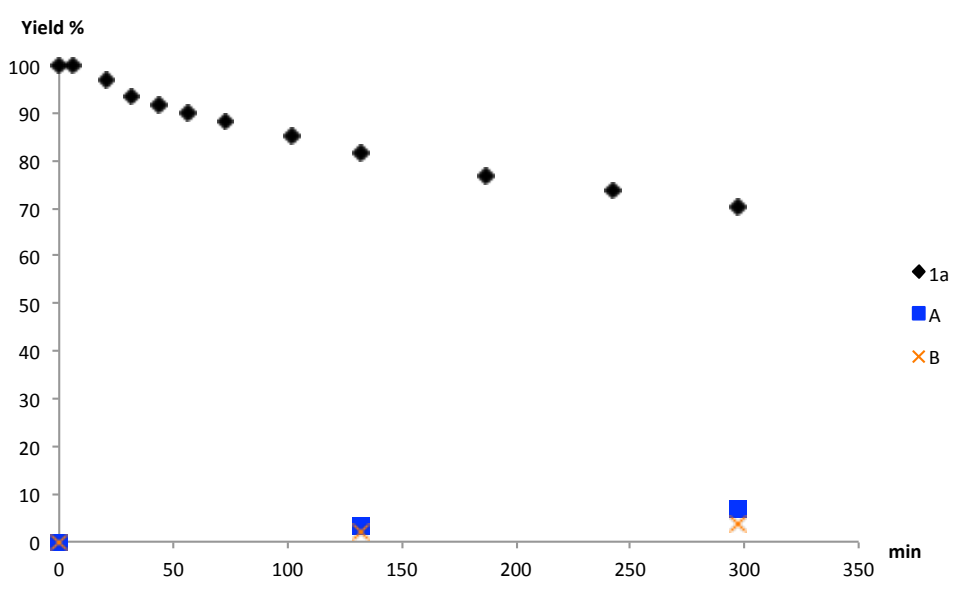

with $30 \%$ TESCF$_{3}$ :

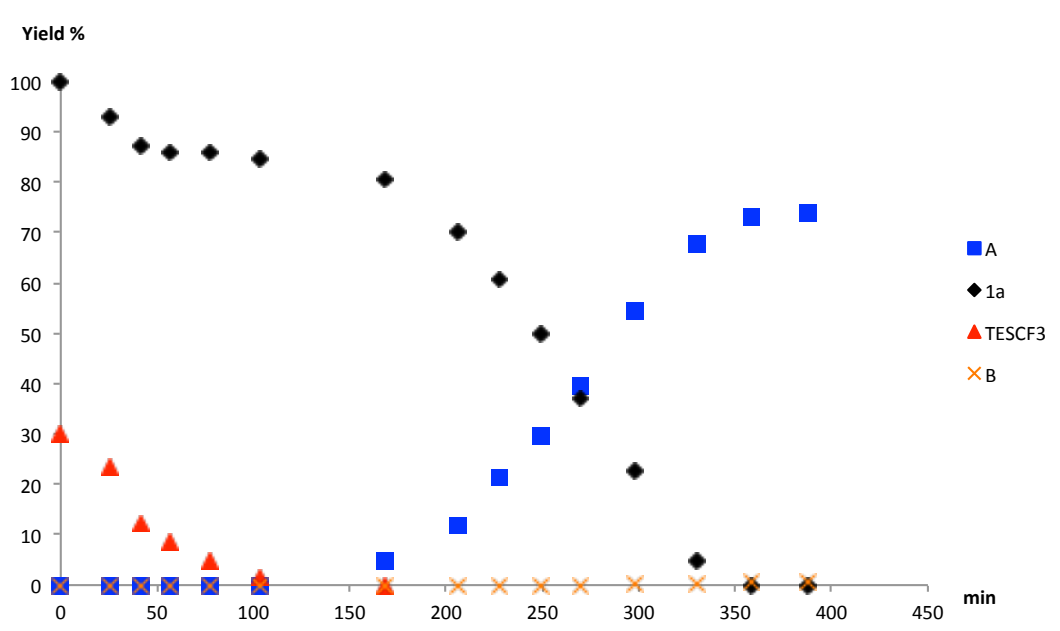

${ }^{a}$ The reaction was conducted at $1.0 \mathrm{mmol}$ scale. Yields were determined by ${ }^{19} \mathrm{~F} \mathrm{NMR}$ analysis of aliquots taken from the reaction mixture using 1-fluoronaphthalene as an internal standard.

\section{Proposed mechanism of the fluorination reaction without $\mathrm{TESCF}_{3}$}

Based on our previous studies on Pd-catalyzed aromatic fluorination, ${ }^{8 \mathrm{~b}}$ we proposed that the catalytic mechanism without any additives is as illustrated in Scheme 2. The productive fluorination process would initiate through the oxidative addition of vinyl triflate $\mathbf{1 a}$ at the phosphine-ligated $\mathrm{Pd}(0)$ species 1 to form L1Pd(vinyl)(OTf) (3). Transmetalation with KF would 
generate $\operatorname{L1Pd}($ vinyl)F (5), and C-F reductive elimination from 5 would provide the fluorinated product A. Alternatively, the Pd(II)-vinyl species, such as $\mathbf{3}$ and 5, could undergo intramolecular deprotonation at the vinylic position to form an L1Pd(II)-cyclohexyne intermediate 6A, eliminating HF in the process. If possible, rapid, reversible isomerization of $6 \mathbf{A}$ into $\mathbf{6 B}$ would explain the formation of the regioisomeric vinyl fluoride product B. Specifically, the reaction of 6B with HF would provide L1Pd(vinyl')F (7B), which could undergo C-F reductive elimination to generate the vinyl fluoride $\mathbf{B}$ with the undesired regioselectivity.

\section{Scheme 2. Proposed Catalytic Cycle for Pd(II)-Catalyzed Fluorination of Cyclic Vinyl} Triflates in the Absence of TESCF $_{3}$.

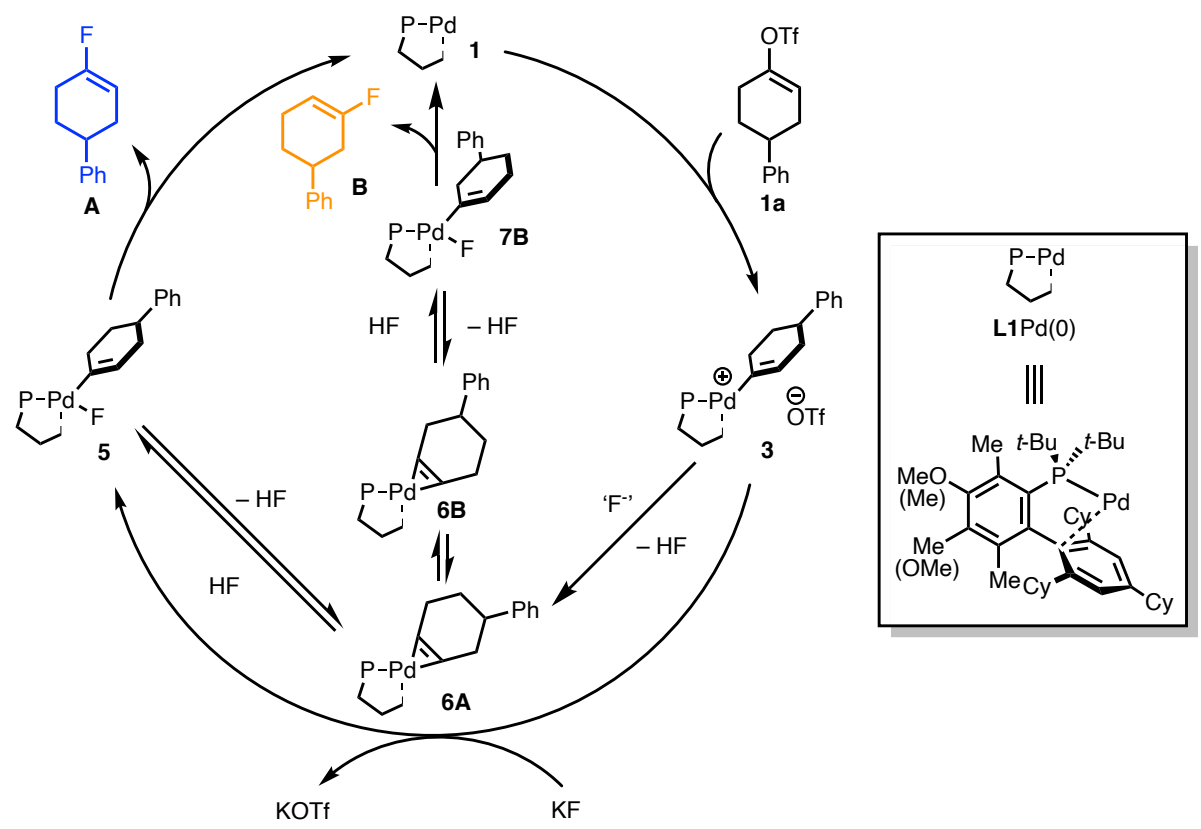

The reversible generation of $6 \mathrm{~A}$ and $\mathbf{6 B}$ would be associated with the liberation of $\mathrm{HF}$, and therefore, we could evaluate the plausibility of this pathway by carrying out the reaction in the presence of an exchangeable deuterium source. ${ }^{9 c}$ Under these conditions, the reaction would presumably form DF in situ, which could recombine with 6A and $6 \mathrm{~B}$ to incorporate deuterium into the appropriate positions of the vinyl fluoride products. When 1.0 equiv of $t$-BuOD was added to the reaction mixture, in addition to the formation of products $\mathbf{A}$ and $\mathbf{B}$, significant amounts of deuterated products $2-\mathbf{A}-d_{1}$ and 2-B- $d_{1}$ were also observed by ${ }^{19} \mathrm{~F}$ NMR and confirmed by GC/MS (Scheme 3a). Additionally, a crossover experiment using 1a and 2,6,6-A- $d_{3}$ provided eight products, representing the isotopologues of $\mathbf{A}$ and those of its regioisomer $\mathbf{B}$ (Scheme $3 \mathrm{~b}$ ). The observed protium-deuterium exchange at the 2-position is consistent with the involvement of the L1Pd(II)-cyclohexyne intermediates (6A and 6B). 
We wanted to test whether the improvements in regioselectivity associated with the addition of $\mathrm{TESCF}_{3}$ might be due to an avoidance of these cyclohexyne intermediates. Thus, we conducted an analogous deuterium-labeling crossover experiment in the presence of $30 \mathrm{~mol} \%$ $\mathrm{TESCF}_{3}$ (Scheme $3 \mathrm{c}$ ). In this experiment, $\mathbf{A}$ and 2,6,6-A- $d_{3}$ were the only fluorination products formed, and no deuterium crossover or regioisomeric products were observed. Thus, the pathways involving L1Pd(II)-cyclohexyne intermediates (6A or 6B) were indeed not operative under these conditions.

\section{Scheme 3. Deuterium Labeling Experiments Under TESCF 3 -Free Conditions. ${ }^{a}$}

(a) OTf

1a

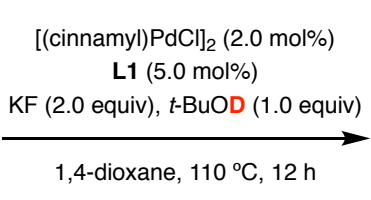

1,4-dioxane, $110^{\circ} \mathrm{C}, 12 \mathrm{~h}$

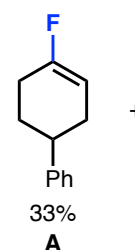

A

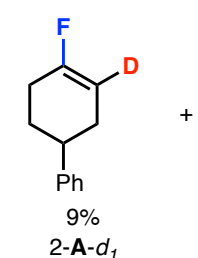

2-A- $d_{1}$
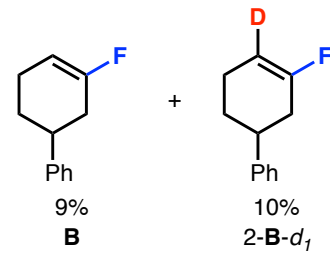

(b)
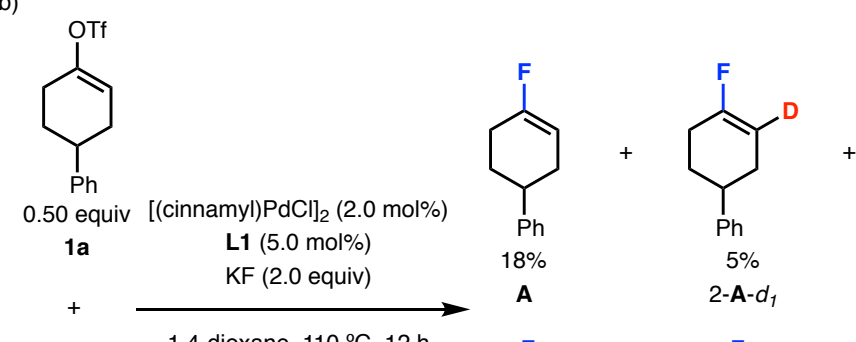<smiles>FC1=CCCC(c2ccccc2)C1</smiles>

$2 \%$

B<smiles>[2H]C1=C(F)CC(c2ccccc2)CC1</smiles>

$6 \%$
-B- $d_{1}$<smiles>[2H]C1=C(O)C([2H])([2H])CC(P)C1</smiles>

0.50 equiv 2,6,6-1a- $d_{3}$
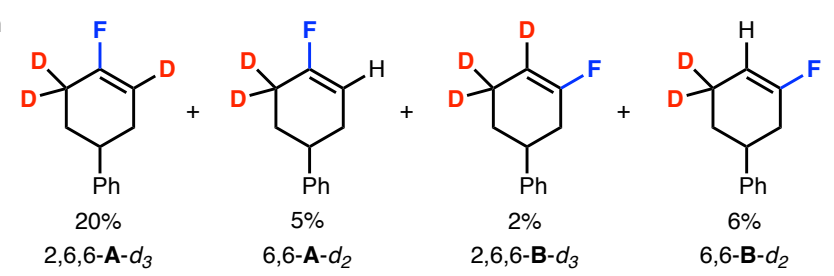

(c)
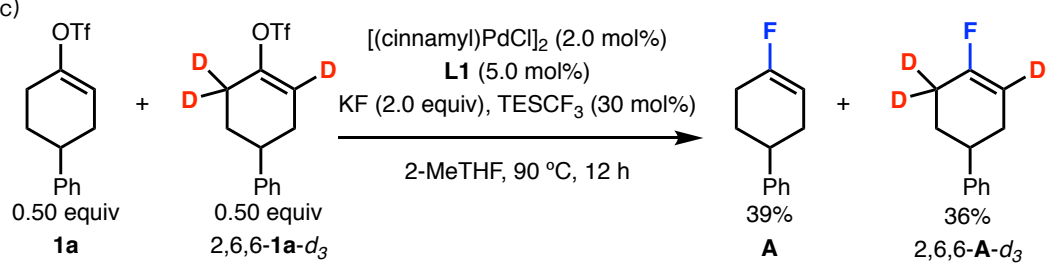

${ }^{a}$ Reactions were run at $0.10 \mathrm{mmol}$ scale and at elevated temperature $\left(11{ }^{\circ} \mathrm{C}\right)$ and 1,4-dioxane to get better yields for analysis. Yields were determined by ${ }^{19} \mathrm{~F}$ NMR analysis of the crude reaction mixture using 1-fluoronaphthalene as an internal standard. In (c), maximum yield is $50 \%$ for each of $\mathbf{A}$ and $\mathbf{A}-d_{3}$. 


\section{DFT Calculations on the Mechanism of the Fluorination Reaction without TESCF 3}

To gain further insight into these experimental observations, we evaluated the proposed mechanism with the aid of density functional theory (DFT) calculations. Geometry optimization, vibration, and solvation energy calculations were performed with M06/LACVP/6-31G** level of theory, and the electronic energies of all optimized structures were reevaluated with M06/LACV3P/cc-pVTZ(-f). ${ }^{14}$ Greater details of the computational methods are given in the supporting information. As shown in Figure 2, $\mathbf{L 1 P d}(0)(\mathbf{1})$ engages 1a through an initial $\pi$ complex 2, from which oxidative addition proceeds with a barrier of $12.7 \mathrm{kcal} / \mathrm{mol}$ (via transition state 2-TS) to afford L1Pd(vinyl)OTf (3). Subsequent dissociation of the triflate counterion from 3 gives the intermediate $\mathbf{L 1 P d}(\text { vinyl })^{+}$(4). The ensuing addition of a fluoride anion to intermediate 4 could potentially provide either the trans-isomer $\mathbf{5}$ or the cis-isomer $\mathbf{5 A}$, in which the name indicates whether fluoride is bound trans or cis to the phosphine ligand, respectively. DFT calculations showed that the trans-isomer $\mathbf{5}$ is $2.4 \mathrm{kcal} / \mathrm{mol}$ lower in energy than $\mathbf{5 A}$ due to the relative trans influences of the ligand on palladium. In addition, the dissociation energy of fluoride from $\mathbf{5}$ is $10.1 \mathrm{kcal} / \mathrm{mol}$ lower than from $\mathbf{5 A}$, indicating $\mathbf{5}$ would be formed dominantly in the reaction. This is consistent with what we observed previously in the aromatic fluorination reactions. $^{8 \mathrm{a}}$

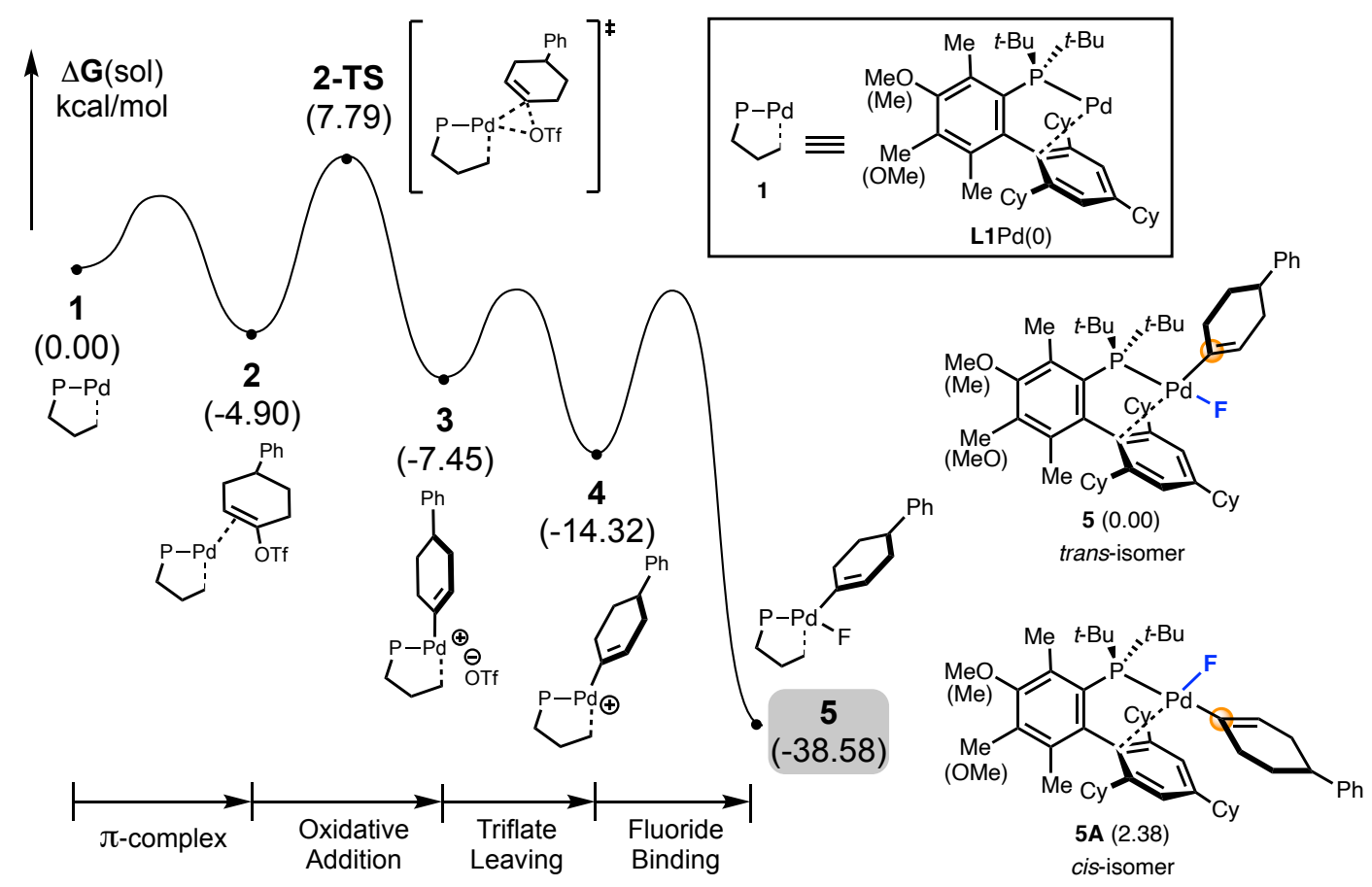

Figure 2. Energy profiles of partial of the proposed mechanism under $\mathrm{TESCF}_{3}$-free conditions with optimized structure of $\mathbf{5}$ and $\mathbf{5 A}$. 
As the trans-isomer $\mathbf{5}$ is the major isomer generated after fluoride association, we considered the reactivity of this complex. As shown in the proposed mechanism (Scheme 2), 5 could either provide the fluorinated product $\mathbf{A}$ via reductive elimination or undergo deprotonation to yield the L1Pd(II)-cyclohexyne intermediate 6A. DFT calculations indicated that the reductive elimination from 5 is associated with a barrier of $24.9 \mathrm{kcal} / \mathrm{mol}$ via $\mathbf{5}$-TS, while the competing deprotonation to form 6A requires a lower activation energy of $22.2 \mathrm{kcal} / \mathrm{mol}$ via 6A-TS (Figure 3). The $2.7 \mathrm{kcal} / \mathrm{mol}$ energy difference favoring deprotonation suggested that the generation of the $\mathbf{L 1 P d}(\mathrm{II})$-cyclohexyne intermediate $\mathbf{6 A}$ is significantly favored over the productive reductive elimination pathway. Once $\mathbf{6 A}$ is formed, it readily rearranges to $\mathbf{6 B}$ through rotation of the cyclohexyne group (via 6AB-TS), with an approximate barrier of $10 \mathrm{kcal} / \mathrm{mol}$. Recombination of 6B and HF generates 7B (the trans-isomer is preferentially formed due to trans influence, see the Supporting Information for details). As with 5, 7B also favors deprotonation, regenerating 6B, rather than reductive elimination. The calculations suggest that a Curtin-Hammett situation is operative in the vinyl fluorination process when additive is absent: $\mathbf{5}$ and $\mathbf{7 B}$ rapidly interconvert via L1Pd(II)-cyclohexyne intermediates, each proceeding slowly but irreversibly to a different isomer of product (A and $\mathbf{B}$, respectively) with low selectivity. 


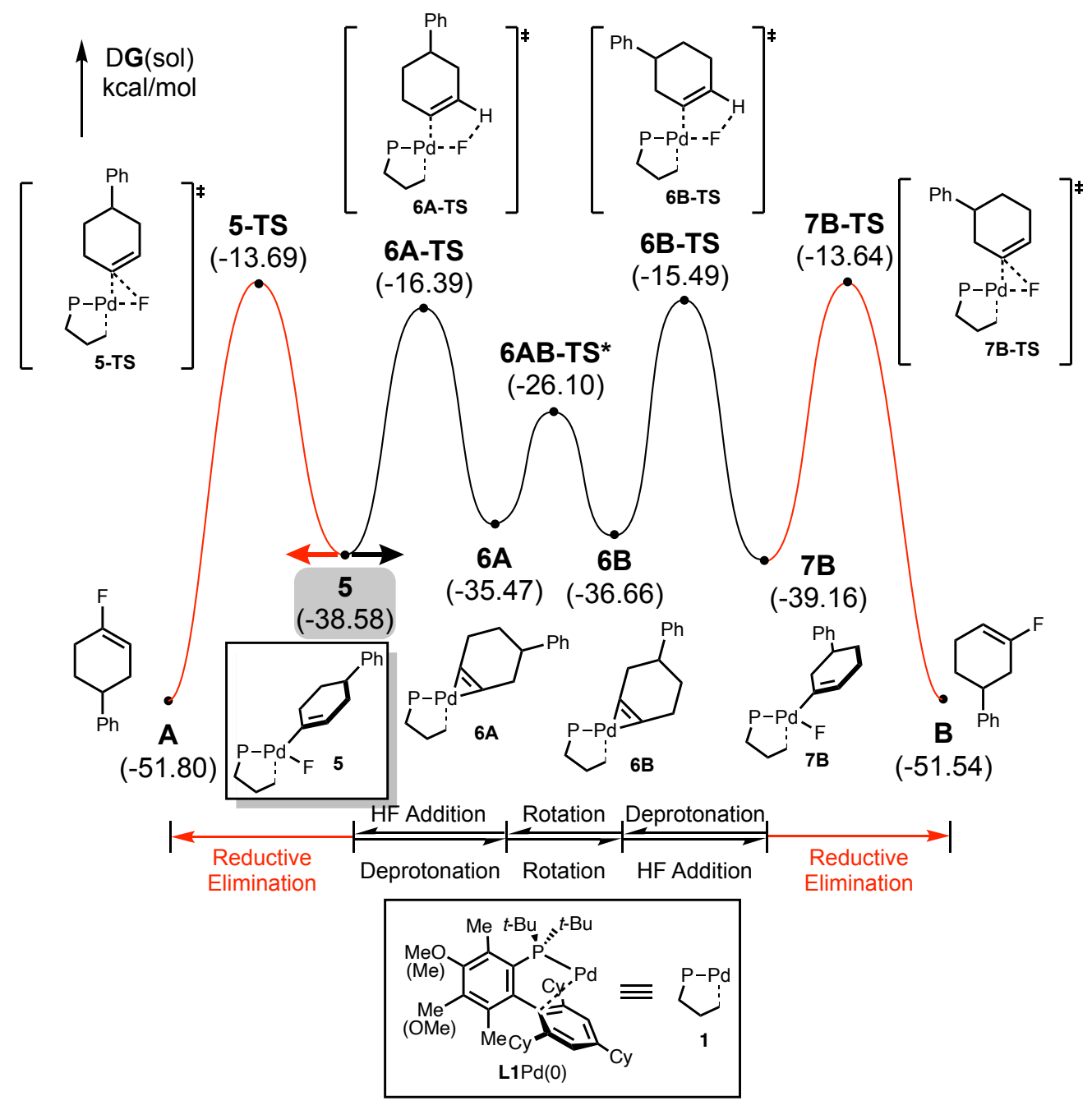

Figure 3. Energy profile of potential transformations of 5.

We tried to prepare the trans-LPd(vinyl)F (5) intermediate and experimentally study its stoichiometric reactivity. As the preparation of $\mathrm{Pd}(\mathrm{II})$ complexes supported by $\mathbf{L} \mathbf{1}$ is difficult, presumably due to the large size of $\mathbf{L 1}$, we employed $\mathbf{L} \mathbf{2}$ as the supporting ligand for these stoichiometric studies (Scheme 4). As previously reported, L2 was also effective in vinyl fluorination, although the regioselectivity of the process was slightly lower than that using L1. ${ }^{12}$ We initially sought to prepare trans-L2Pd(vinyl)F (C2) from trans-L2Pd(vinyl) $\mathrm{Br}$ (C1) via salt metathesis with $\mathrm{AgF}$. When $\mathbf{C} 1$ was treated with $\mathrm{AgF}$, fluorinated products $\mathbf{A}$ and $\mathbf{B}$ were readily formed, even at room temperature. This relatively rapid formation of product demonstrates the ability of bulky biarylphosphine ligands to facilitate $\mathrm{C}-\mathrm{F}$ reductive elimination from $\mathrm{Pd}(\mathrm{II})$ complexes at ambient temperature. When the metathesis reaction was attempted in 2-MeTHF at $90{ }^{\circ} \mathrm{C}$, which is the combination of solvent and temperature used in the catalytic reaction, $\mathbf{A}$ and $\mathbf{B}$ were generated in $26 \%$ and $25 \%$ yields, respectively, as assessed by ${ }^{19} \mathrm{~F}$ NMR. This observation is 
consistent with the estimated theoretical regioselectivity $(1: 1)$ based on the computed energies using L2 (see the Supporting Information for details).

\section{Scheme 4. Stoichiometric Study on the Reductive Elimination of C2.}

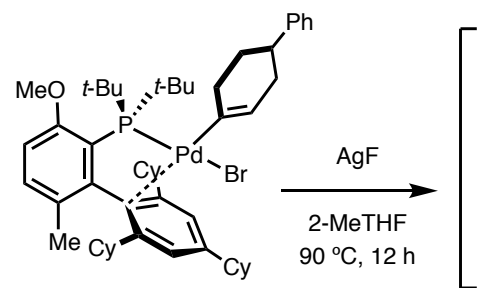

C1

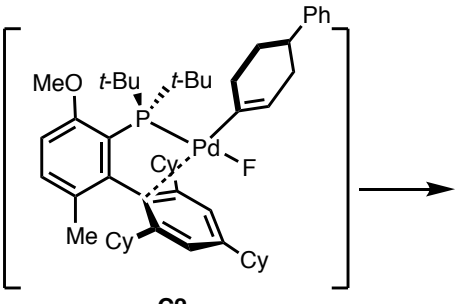

C2

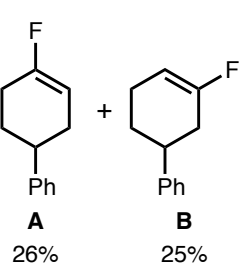

$\mathbf{A}: \mathbf{B}=1: 1$

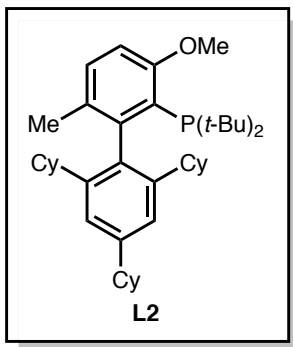

One Potential Role of TESCF 3 Additive: Formation of LPd-CF $\mathrm{LPecies}_{3}$

With an understanding of the fluorination process absent any additives, we then considered the potential role of $\mathrm{TESCF}_{3}$ additive in the fluorination reaction. We envisioned that the $\mathrm{CF}_{3}{ }^{-}$ released from $\mathrm{TESCF}_{3}$ under the fluorination conditions might attack $\mathbf{L} 1 \mathrm{Pd}\left(\right.$ vinyl) ${ }^{+}$(4) to generate the $\mathbf{L} 1 \mathrm{Pd}\left(\right.$ vinyl) $\mathrm{CF}_{3}$ complex, as was proposed in Pd-catalyzed trifluoromethylation reactions (Scheme 5, 8). ${ }^{15-18}$ In a potential unproductive pathway, 8 could undergo reductive elimination to provide the trifluoromethylated side product $\mathbf{C}$ (Scheme 5, reductive elimination). However, even in the presence of 1.0 equiv of $\mathrm{TESCF}_{3}$, only trace amounts of side product $\mathbf{C}$ were observed in the fluorination reaction. Alternatively, $\mathbf{8}$ might serve as a precursor for an in situ modified ligand with improved catalytic activity and selectivity. Previously, in Pd-catalyzed aromatic fluorination reactions, we observed that the oxidative addition complex $t$-BuBrettPhosPd(4- $\left.n-\mathrm{Bu}_{-} \mathrm{C}_{6} \mathrm{H}_{4}\right) \mathrm{Br}($ D1) underwent a dearomative rearrangement to generate D2, which upon deprotonation formed ligandmodified species L3Pd (Scheme 6). ${ }^{9 a}$ This complex, based on modified ligand $\mathbf{L 3}$, is believed to be the active catalyst throughout most of the palladium-catalyzed aryl fluorination process. We hypothesized that 8 could undergo a similar dearomative rearrangement to generate ligands that are modified by the addition of an alkenyl or trifluoromethyl group (Scheme 5, rearrangement). We therefore sought to independently prepare these modified ligands and evaluate the reactivity and selectivity of reactions using catalysts based on them. For ease of synthesis, ligand L4, which is structurally similar to $\mathbf{L} 1$ and which was also associated with a significant $\mathrm{TESCF}_{3}$ effect in the fluorination reactions, was employed in the fluorination reaction and compared against its trifluoromethylated and alkenylated analogs (Table 1, entry 1 and 2). ${ }^{19}$ The use of neither of these modified ligands showed results comparable to the use of $\mathbf{L 4}$ as the ligand with $\mathrm{TESCF}_{3}$ as the additive. When the cyclohexenyl-modified version of L4 (L4-vinyl) was used under TESCF 3 -free conditions, the reaction afforded the fluorinated products in $14 \%$ combined yield with 1.8:1 
regioselectivity (Table 1, entry 3). The use of $\mathrm{CF}_{3}$-modified ligand $\mathbf{L 4}-\mathbf{C F}_{\mathbf{3}}$ under the same reaction conditions gave trace amount of the fluorination products (Table 1, entry 4). Moreover, when $\mathrm{TESCF}_{3}$ was added to reactions using either $\mathbf{L} 4$-vinyl or $\mathbf{L} 4-\mathbf{C F}_{\mathbf{3}}$ as the ligands, although less significant than the standard reaction condition using L1, improvements in regioselectivity and reactivity were observed (Table 1, entry 5 and 6). Together, these experiments suggest that an in situ 3'-substitution of the phosphine ligand did not account for the observed $\mathrm{TESCF}_{3}$ effect.

Accordingly, we had to consider that the $\mathrm{Pd}_{-} \mathrm{CF}_{3}$ intermediate $\mathbf{8}$ may not be formed at all in this fluorination process. The rigidity of the ligand backbone and the steric hindrance of the two tert-butyl groups on the phosphorous of these ligands ( $\mathbf{L} 1$ and $\mathbf{L 2})$ might render $\mathrm{CF}_{3}{ }^{-}$attack on the cationic $\mathrm{Pd}(\mathrm{II})$ center rather slow. ${ }^{20 \mathrm{a}, \mathrm{b}}$ Consistent with this observation, palladium catalysts bearing $\mathrm{P} t$ - $\mathrm{Bu}_{2}$ ligands have been observed to be incompetent for $\mathrm{Pd}^{0 / I I}$-catalyzed aryl trifluoromethylation, despite the associated $\mathrm{C}-\mathrm{CF}_{3}$ reductive elimination barrier being thermally accessible. ${ }^{20 \mathrm{c}}$

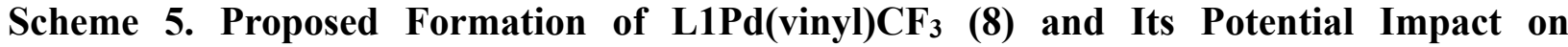 Fluorination Process.}

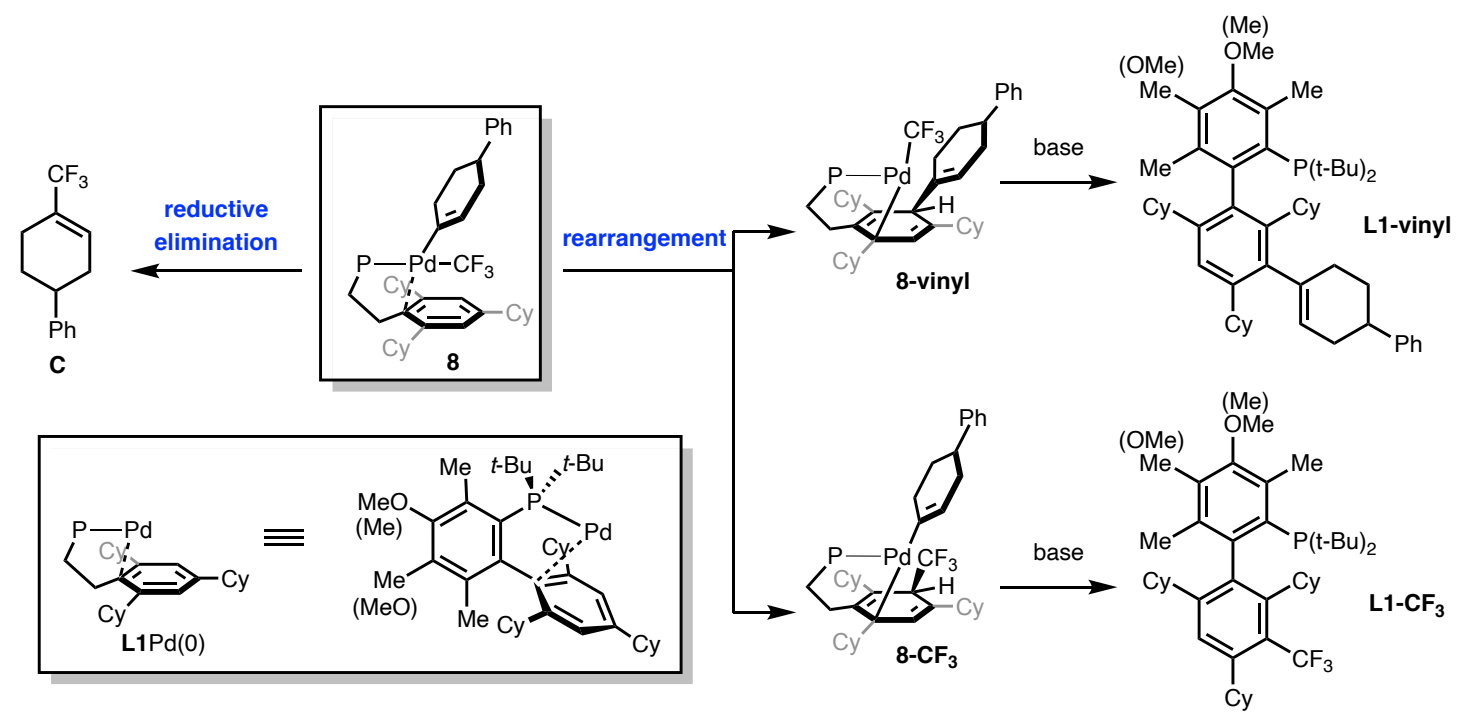


Scheme 6. Dearomative Rearrangement of the Oxidative Addition Complex in the Fluorination of Aryl Bromides.

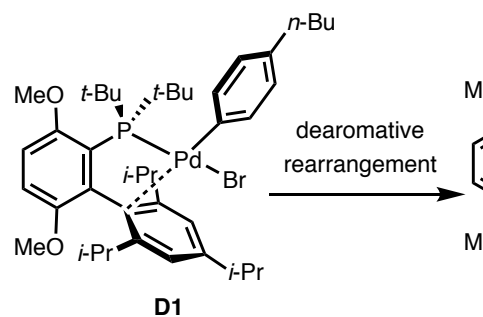

$t$-BuBrettPhos $\mathrm{Pd}(n-\mathrm{BuPh}) \mathrm{Br}$

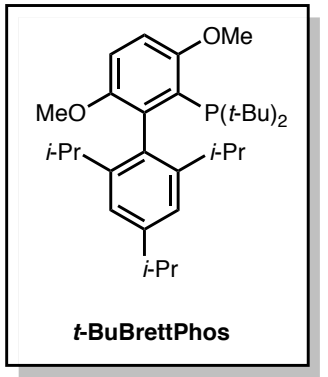

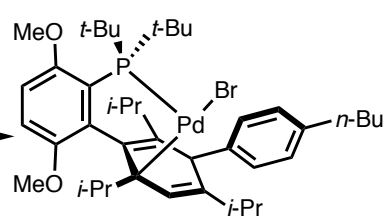

D2

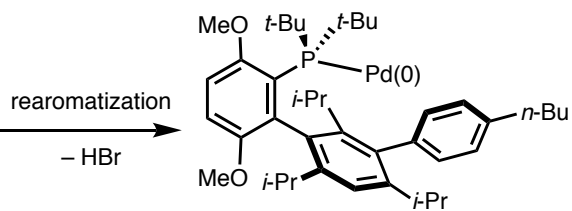

L3Pd

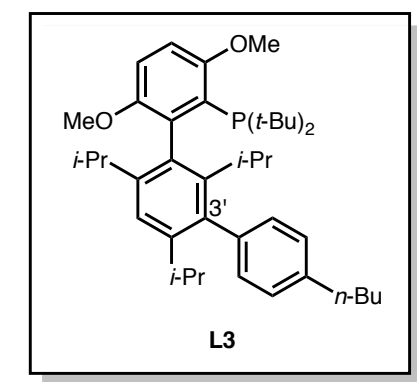

Table 1. Fluorination Reaction Employing Ligand L4, L4-vinyl and L4-CF 3 .

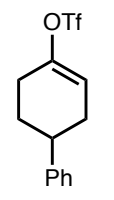

$1 a$

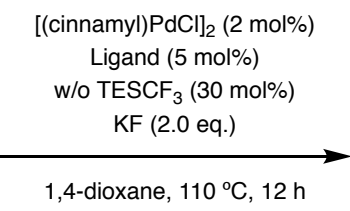

1,4-dioxane, $110^{\circ} \mathrm{C}, 12 \mathrm{~h}$<smiles>FC1=CCCC(c2ccccc2)C1</smiles>

A

B

\begin{tabular}{|c|c|c|c|c|}
\hline entry & ligand and $\mathrm{TESCF}_{3}$ & $\mathbf{A}(\%)$ & B $(\%)$ & $\mathbf{A}: \mathbf{B}$ \\
\hline 1 & L4 & 11 & 8 & $1.4: 1$ \\
\hline 2 & $\mathbf{L}_{4}+\mathbf{T E S C F}_{3}$ & 56 & 6 & $9.3: 1$ \\
\hline 3 & L4-vinyl & 9 & 5 & $1.8: 1$ \\
\hline 4 & $\mathrm{~L}_{4}-\mathrm{CF}_{3}$ & trace & trace & / \\
\hline 5 & L4-vinyl $+\mathrm{TESCF}_{3}$ & 67 & 3 & $22: 1$ \\
\hline 6 & $\mathbf{L} \mathbf{4}-\mathbf{C F}_{\mathbf{3}}+\mathrm{TESCF}_{3}$ & 21 & 2 & $11: 1$ \\
\hline & L4 & L4-vinyl & $F_{3}$ & \\
\hline
\end{tabular}


${ }^{a}$ Reactions were run at $0.10 \mathrm{mmol}$ scale. Yields were determined by ${ }^{19} \mathrm{~F} \mathrm{NMR}$ analysis of the crude reaction mixture using 1-fluoronaphthalene as an internal standard.

\section{An Alternative Role of TESCF 3 : Ligand Dearomatization}

In searching for other potential roles for $\mathrm{TESCF}_{3}$, our attention was drawn to a 2012 report from Amgen chemists in which they observed the generation of complex E1 (Scheme 7a, E1) with a dearomatized ligand during Pd-catalyzed cross-coupling. ${ }^{21 \mathrm{a}}$ It was proposed that the dichlorocarbene, which formed from chloroform under basic conditions, attacked the bottom ring of $t$-BuXPhos and formed a bond at the para-position, on the face anti to the palladium. In 2014, our group also observed a similar dearomatized complex when exposing AdBrettPhos-Pd(0) to $\mathrm{CDCl}_{3}$ (Scheme 7b, E2). ${ }^{21 b, c}$ We wondered if such an analogous process could occur in the fluorination reaction wherein the trifluoromethyl anion $\left(\mathrm{CF}_{3}{ }^{-}\right)$or the difluorocarbene $\left(: \mathrm{CF}_{2}\right)$ attacks the para-position of the bottom ring of the ligand. We found experimentally that in the presence of $\mathrm{TMSCF}_{3}$ and a fluoride source, a dearomatized $\mathrm{Pd}(\mathrm{II})$ complex supported by $t$-BuXPhos was generated in approximately $30 \%$ yield in two steps (Scheme 7c, F). Single-crystal X-ray diffraction structure analysis demonstrated that $\mathbf{F}$ was structurally similar to $\mathbf{E 1}$ and $\mathbf{E 2}$. In this case, the structure possesses an $\alpha$-disposed $\mathrm{CF}_{3}$ substituent at $\mathrm{C} 4$ position of a dearomatized ring, while the $\operatorname{Pd}$ center binds to the dienyl system in an $\eta^{3}$ fashion. 


\section{Scheme 7. Discovery of Pd Complexes Supported by Dearomatized Ligand.}

a)
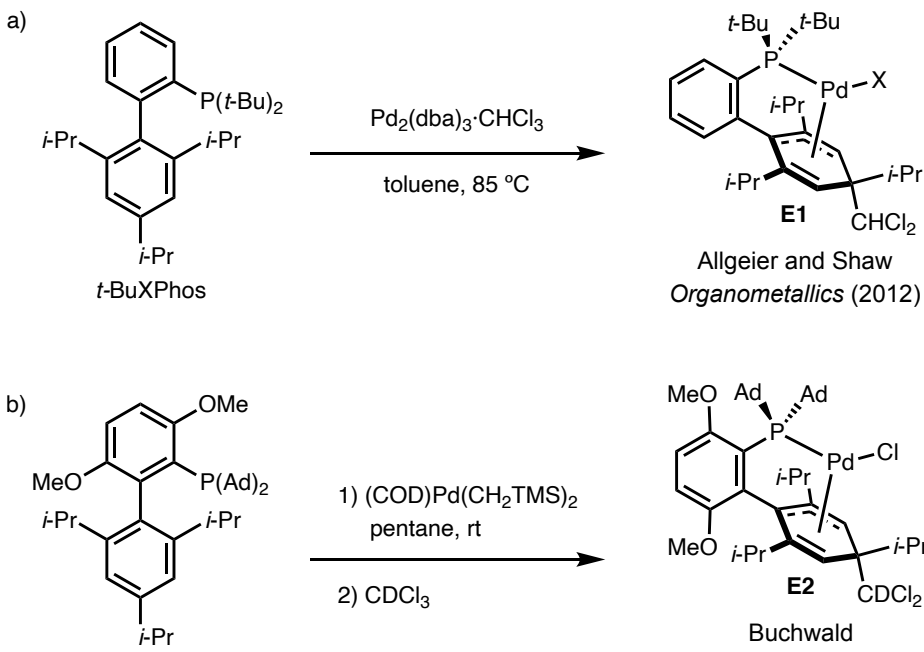

1) (COD) $\mathrm{Pd}\left(\mathrm{CH}_{2} \mathrm{TMS}\right)_{2}$ pentane, $\mathrm{rt}$

2) $\mathrm{CDCl}_{3}$

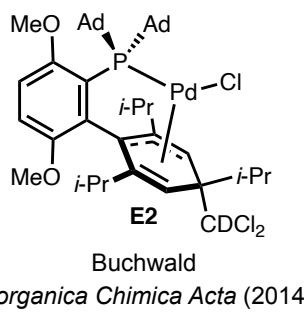

c)

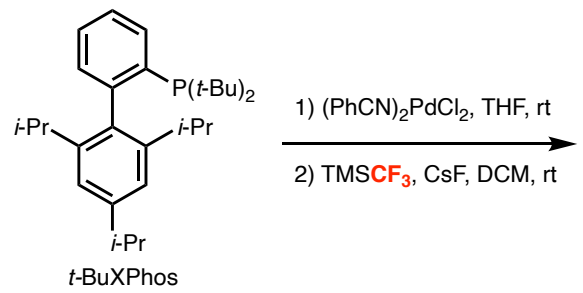

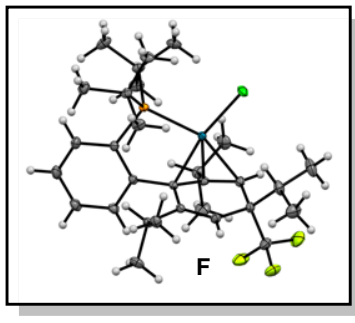

Using $\mathbf{L} \mathbf{1}$ as the supporting ligand, however, we were not able to prepare any of the $\mathrm{Pd}(\mathrm{II})$ complexes stoichiometrically, presumably due to the extreme steric properties of the ligand. Thus, in order to investigate the plausibility of this dearomative process for L1 and its potential consequences on the fluorination process, DFT calculations were performed (Figure 4). Starting from 4', we found that the addition of $\mathrm{CF}_{3}{ }^{-}$to the bottom ring of the ligand demands an activation energy of $10.5 \mathrm{kcal} / \mathrm{mol}$ via transition state $\mathbf{4}^{\prime}-\mathbf{T S}^{*}$ to form a dearomatized intermediate $\mathbf{6}^{20 \mathrm{~b}, 22}$ The barrier indicates the dearomatization process is possible for $\mathbf{L} \mathbf{1}$ under the fluorination reaction conditions. Further, because 4' is a cationic complex, this dearomative process releases a substantial amount of energy $(29.1 \mathrm{kcal} / \mathrm{mol})$.

After the generation of $\mathbf{6}$, reaction with a fluoride anion would form intermediate $\mathbf{7}$ or $\mathbf{7}$, where the fluoride is bound either in cis or trans-position to the phosphine ligand. Unlike in the case of $\mathbf{5}$ and $\mathbf{5 A}$ where the trans-isomer $\mathbf{5}$ is more stable, we found that the cis-isomer $\mathbf{7}$ is energetically preferred by a substantial amount $(2.3 \mathrm{kcal} / \mathrm{mol}){ }^{23}$ Once formed, 7 would then eliminate the $\mathrm{CF}_{3}{ }^{-}$through 7-TS* to provide the corresponding cis-isomer 5A. The overall barrier of 7-TS* from 6 is calculated to be $32.4 \mathrm{kcal} / \mathrm{mol}$ and is $2.4 \mathrm{kcal} / \mathrm{mol}$ lower than 7'-TS* which gives 5 . 


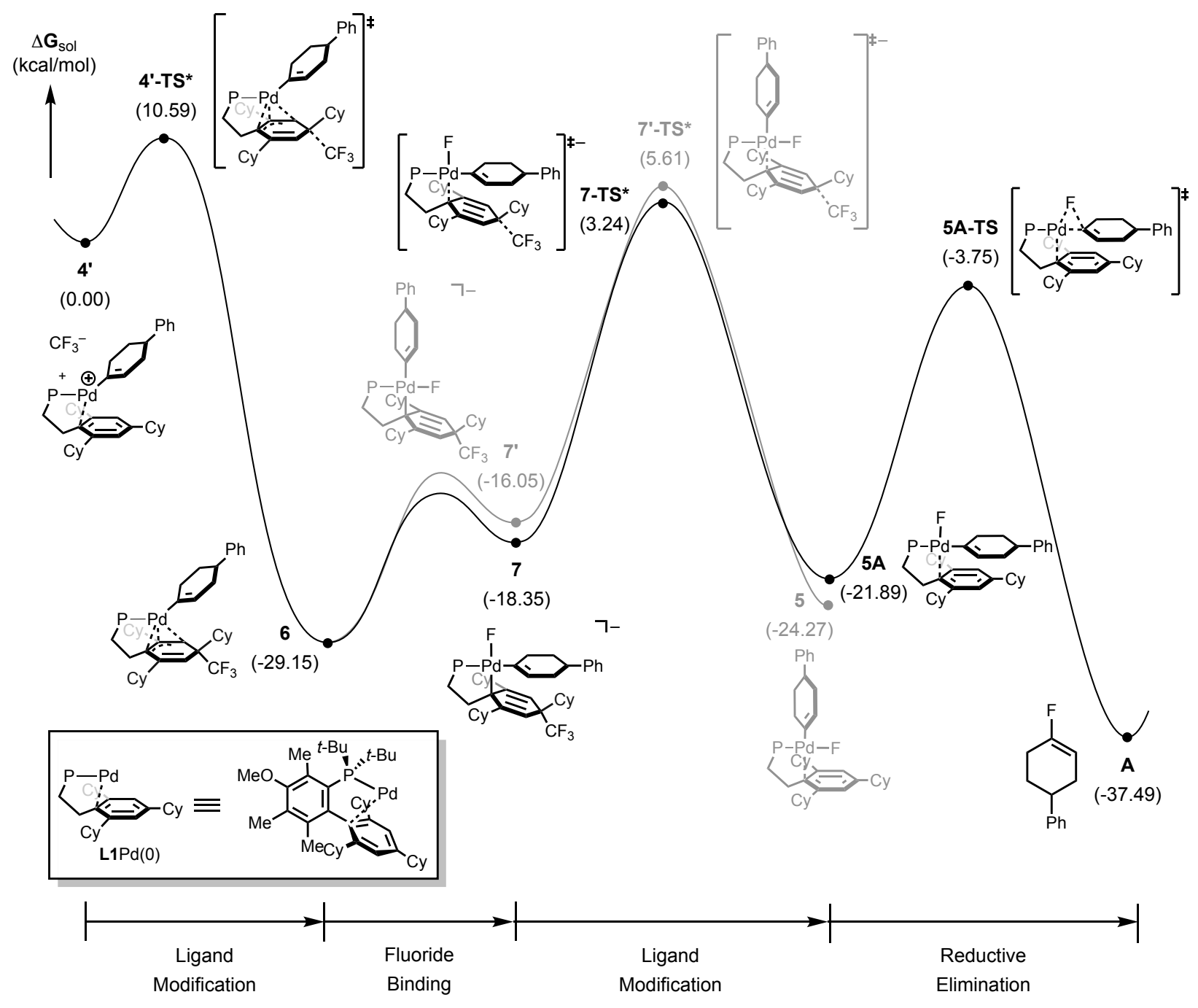

Figure 4. Energy profile of the proposed dearomatization reaction between $\mathrm{CF}_{3}^{-}$and 4. (* represents an estimated barrier. See the Supporting Information for the details)

Interestingly, when we investigated the reactivity of $\mathbf{5 A}$ toward either $\beta$-deprotonation or reductive elimination, we found that $\mathbf{5 A}$ displays the opposite selectivity to that manifested by $\mathbf{5}$. As summarized in Scheme 8, the reductive elimination barrier of $\mathbf{5 A}$ is calculated to be 7.3 $\mathrm{kcal} / \mathrm{mol}$ lower than that of $\beta$-deprotonation pathway, while $\mathbf{5}$ prefers $\beta$-deprotonation. This suggested that $\mathbf{5 A}$ should undergo facile and regioselective reductive elimination to provide the fluorinated product A, and no L1Pd(II)-cyclohexyne intermediates should be generated (Figure 4). Of importance, the barrier to isomerization between $\mathbf{5}$ and $\mathbf{5 A}$ was calculated to be $\sim 23.6 \mathrm{kcal} / \mathrm{mol}$, which is higher than either 6A-TS or 5A-TS, suggesting that isomerization is unlikely under the reaction conditions that were employed (see Figure $2 \mathrm{~S}$ in the Supporting Information for more details). 
Scheme 8. Reaction Preferences of 5 and 5A.
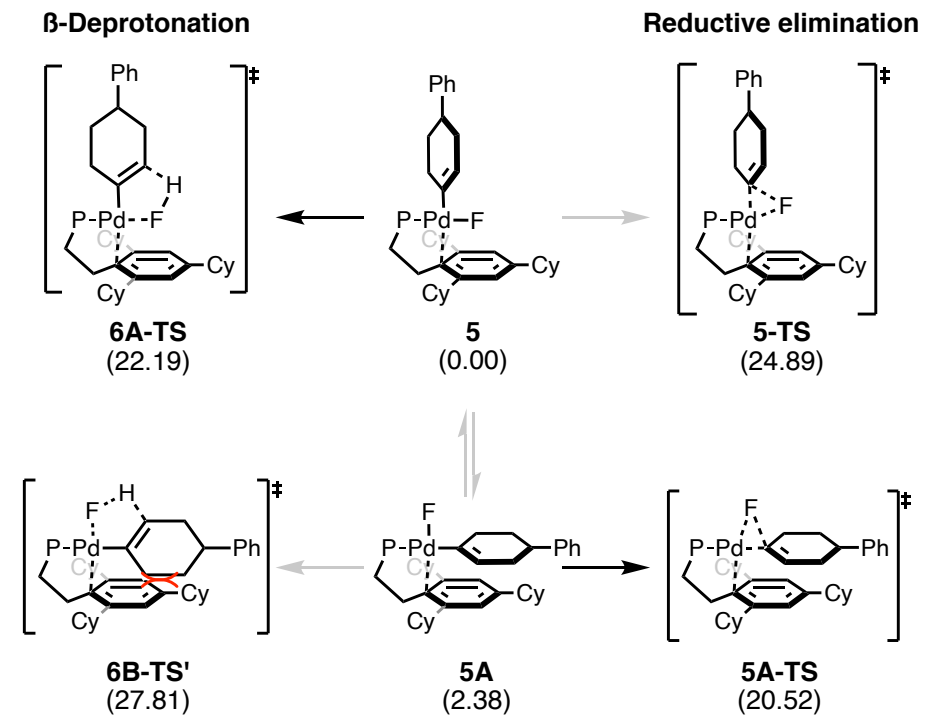

Based on these results, a proposed mechanism for the fluorination of vinyl triflates with $\mathrm{TESCF}_{3}$ as an additive is illustrated in Scheme 9. During the induction period, $\mathrm{TESCF}_{3}$ releases $\mathrm{CF}_{3}{ }^{-}$. Most of them would be expected to decompose unproductively to form $\mathrm{CHF}_{3}$ or $\mathrm{CF}_{2} \mathrm{CF}_{2}$. Some, however, can react with $\mathbf{4}$, which was generated after oxidative addition of $\mathbf{1}$ with the starting material 1a, to provide the dearomatized intermediate $\mathbf{6}$. The fluoride anion would then react with 6 to form intermediate 7, which subsequently ejects $\mathrm{CF}_{3}{ }^{-}$to generate the cisL1Pd(vinyl)F 5A. 5A would undergo reductive elimination to provide the vinyl fluoride $\mathbf{A}$ with the desired regioselectivity. Essentially, in the fluorination process with $\mathrm{TESCF}_{3}$ as an additive, the $\mathrm{CF}_{3}{ }^{-}$released actually functions to facilitate the formation of $\mathbf{5 A}$, which is responsible for the improved regioselectivity of the reaction. 
Scheme 9. Proposed Fluorination Mechanism in the Presence of TESCF 3 .

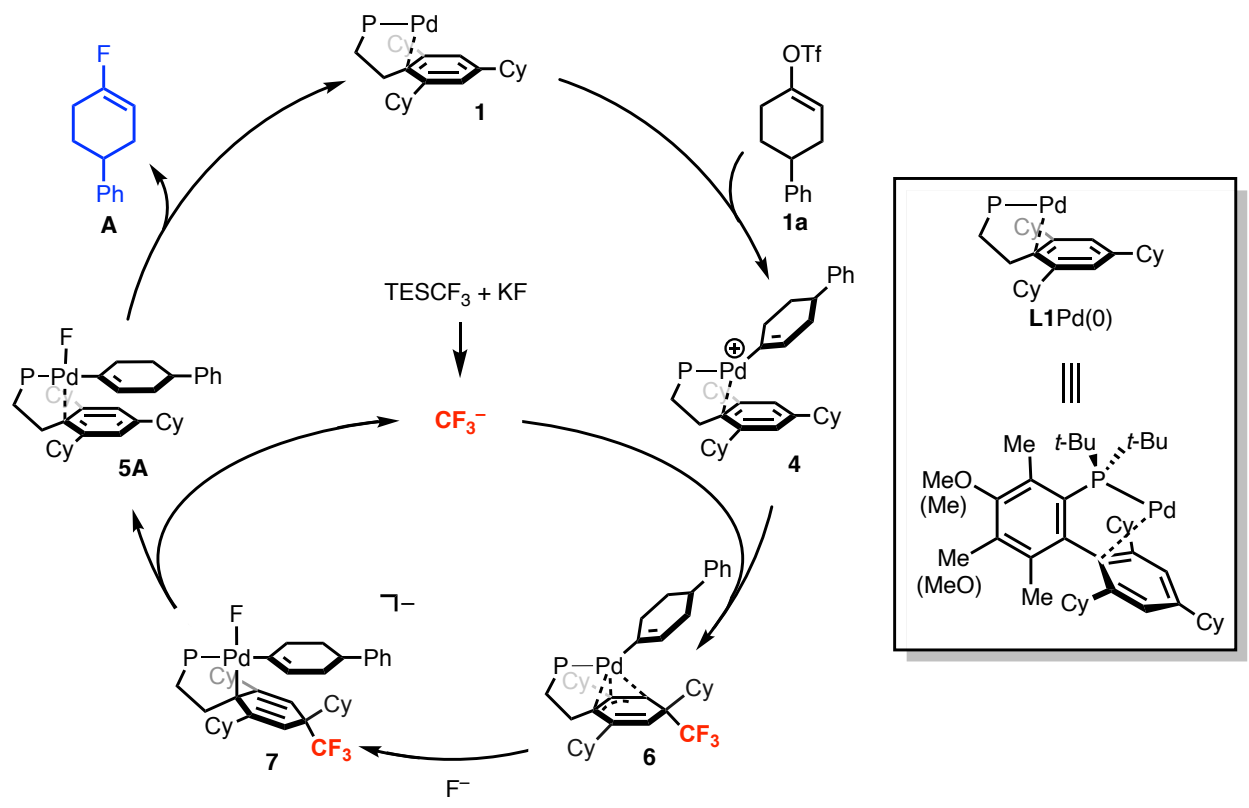

In order to obtain experimental evidence for the formation of dearomatized intermediate $\mathbf{6}$, we designed a fluoro-substituted ligand L5, which could be employed as a probe to determine whether the bottom ring of the ligand ever undergoes nucleophilic attack by $\mathrm{CF}_{3}{ }^{-}$(Scheme 10). We hypothesized that in the reaction using $\mathbf{L 5}$ as the ligand and $\mathrm{TESCF}_{3}$ as an additive, in a manner analogous to the formation of intermediate $\mathbf{6}$ when $\mathbf{L 1}$ was used, the corresponding intermediate $3 F-6$ would be generated. In the presence of fluoride, $3 F-6$ could be converted to $3 F-7$, which would undergo rearomatization by losing $\mathrm{a} \mathrm{CF}_{3}{ }^{-}$to generate $\mathbf{L 5 - 5 \mathrm { A }}$. Alternatively, $3 F-7$ could also rearomatize by losing a $\mathrm{F}^{-}$to form $\mathbf{L 6 - 5 A}$. If the latter pathway is followed, a new ligand $\mathbf{L 6}$, in which one fluorine was substituted by a trifluoromethyl group, would be generated. When L5 was used as the ligand in the fluorination reaction using $\mathrm{TESCF}_{3}$ as the additive, the fluorinated product was formed in $34 \%$ yield with $>20: 1$ regioselectivity. ${ }^{31} \mathrm{P}$ NMR analysis of the crude reaction mixture showed that most of the $\mathbf{L 5}$ remained unchanged, and the formation of $\mathbf{L 6}$ could not be verified. However, when we analyzed the crude reaction reaction mixture by HRMS, we unambiguously identified a new peak corresponding to $\mathbf{L 6}\left(\left[\mathbf{L 6}+\mathrm{H}^{+}\right]=543.3174\right.$, found 543.3187, see the Supporting Information for more details). This peak was not seen in control experiments in which either the Pd source or the triflate starting material were omitted, which is consistent with L6 being formed through the pathway proposed in Scheme 10. Participating by the Pd center may cause $3 F-7$ to preferentially undergoe rearomatization by losing a $\mathrm{CF}_{3}{ }^{-}$from the anti face of the aromatic system rather than $\mathrm{a} \mathrm{F}^{-}$group from the syn face. Again, these results are consistent with the proposed in situ ligand dearomatization by $\mathrm{CF}_{3}{ }^{-}$under the fluorination conditions. 
Scheme 10. Generation of Pd complexes Supported by ligand with a dearomatized bottom ring.

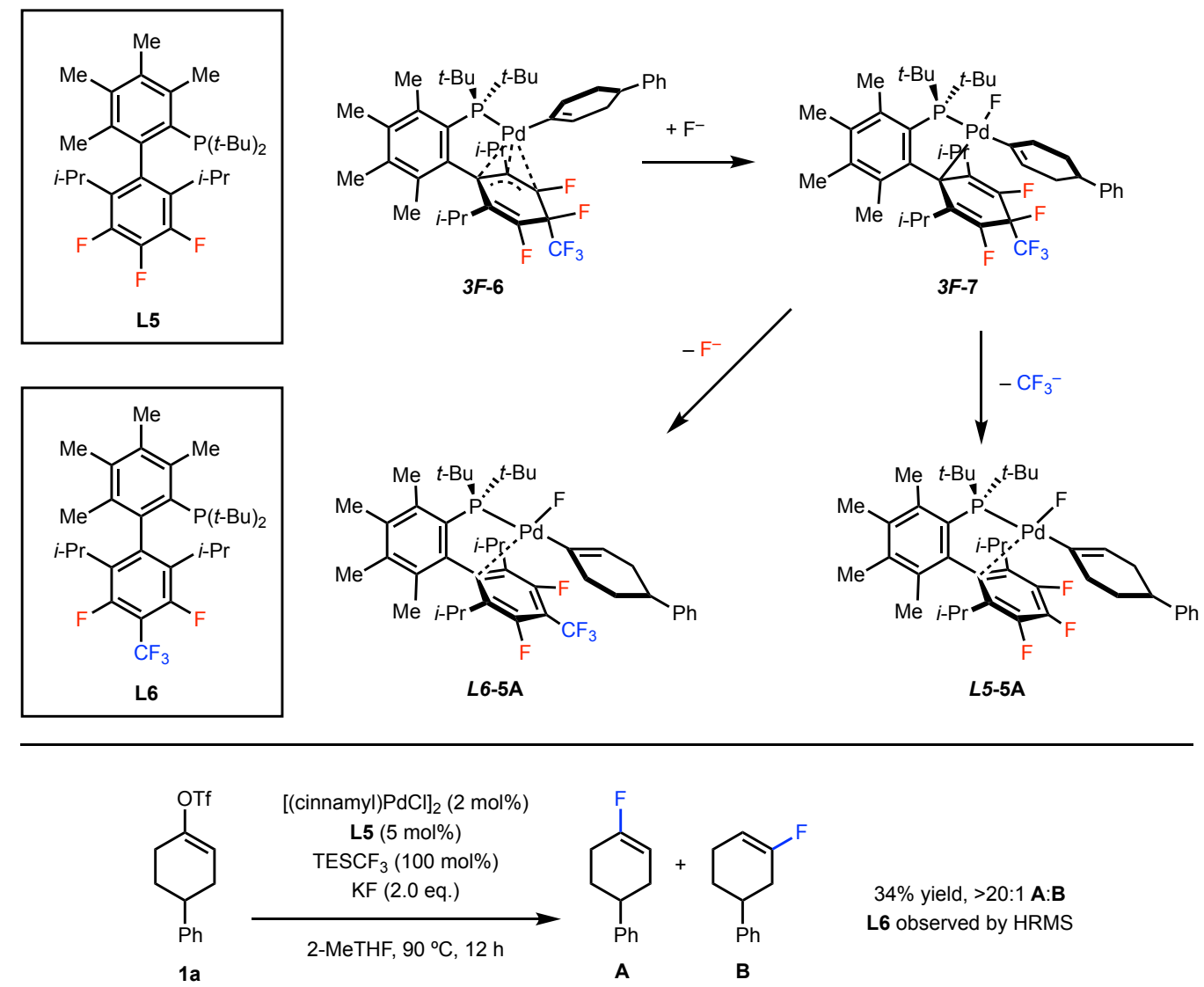

\section{Conclusion}

In summary, we have investigated the mechanism of the Pd-catalyzed fluorination of cyclic vinyl triflates in the absence or presence of $\mathrm{TESCF}_{3}$ additives. A combined experimental and computational study suggested that when no $\mathrm{TESCF}_{3}$ was added, a Curtin-Hammett situation is operative during the fluorination process, which was responsible for the observed low yield and regioselectivity. In the presence of $\mathrm{TESCF}_{3}$, an alternative pathway involving an unusual dearomatization of the ligand by nucleophilic attack from a $\mathrm{CF}_{3}{ }^{-}$was proposed on the basis of literature precedents and our DFT calculations. Although the stoichiometric preparation and isolation of the dearomatized intermediate was unsuccessful, our results are fully consistent with the hypothesized mechanism.

The significant influence of the cis/trans-geometry of Pd(II) fluoride intermediates on the reaction outcome is the key to understanding this fluorination process and the additive effect. The trans-isomer (5) preferentially undergoes $\beta$-deprotonation, which ultimately produces mixtures of product isomers. In contrast, the $c$ is-isomer $\mathbf{( 5 A}$ ) undergoes facile reductive elimination rather than 
$\beta$-deprotonation to provide the fluorinated product without isomerization. The presence of $\mathrm{CF}_{3}{ }^{-}$in the reaction is believed to disfavor the formation of the trans-isomer (5) through temporary dearomatization of the bottom aryl ring of the ligand. Finally, the unusual transmetalation mechanism disclosed in this study involving an in situ ligand modification pathway might be relevant in other cross-coupling processes employing bulky biarylphosphine-derived Pd catalysis.

\section{Associated Content}

\section{Supporting Information}

The Supporting Information is available free of charge on the ACS Publications website.

Experimental details and computational data (PDF)

Spectroscopic Data (PDF)

\section{Author Information}

Corresponding Author

*mbaik2805@kaist.ac.kr

*sbuchwal@mit.edu

\section{Author Contributions}

Y. Ye and S.-T. Kim contributed equally.

\section{Notes}

The authors declare no competing financial interests.

\section{Acknowledgements}

We are grateful to the National Institutes of Health (R35-GM122483), and the Institute for Basic Science (IBS-R010-A1) in Korea. The content is solely the responsibility of the authors and does not necessarily represent the official views of the National Institute of Health. We thank Drs. Richard Liu, Scott McCann, Christine Nguyen, Alex Schuppe, Yang Yang for their advice on the preparation of this manuscript. We acknowledge Charlene Tsay (MIT) for X-ray crystallographic analysis. 


\section{References}

(1) O'Hagan, D. Understanding Organofluorine Chemistry. An Introduction to the C-F Bond. Chem. Soc. Rev. 2008, 37, 308-319.

(2) (a) Wang, J.; Sánchez-Roselló, M.; Aceña, J. L.; delPozo, C.; Sorochinsky, A. E.; Fustero, S.; Soloshonok, V. A.; Liu, H. Fluorine in Pharmaceutical Industry: Fluorine-Containing Drugs Introduced to the Market in the Last Decade (2001-2011). Chem. Rev. 2014, 114, 2432-2506. (b) Zhou, Y.; Wang, J.; Gu, Z.; Wang, S.; Zhu, W.; Aceña, J. L.; Soloshonok, V. A.; Izawa, K.; Liu, H. Next Generation of Fluorine-Containing Pharmaceuticals, Compound Currently in Phase II-III Clinical Trials of Major Pharmaceutical Companies: New Structural Trends and Therapeutic Areas. Chem. Rev. 2016, 116, 422-518. (c) Yamazaki, T.; Taguchi, T.; Ojima, I. Unique Properties of Fluorine and their Relevance to Medicinal Chemistry and Chemical Biology. In Fluorine in Medicinal Chemistry and Chemical Biology; John Wiley \& Sons: Chichester, U.K., 2009.

(3) Jeschke, P. The Unique Role of Fluorine in the Design of Active Ingredients for Modern Crop Protection. ChemBioChem 2004, 5, 570-589.

(4) (a) Gillis, E. P.; Eastman, K. J.; Hill, M. D.; Donnelly, D. J.; Meanwell, N. A. Applications of Fluorine in Medicinal Chemistry. J. Med. Chem. 2015, 58, 8315-8359. (b) Hagmann, W. K. The Many Roles for Fluorine in Medicinal Chemistry. J. Med. Chem. 2008, 51, 4359-4369.

(5) Balz-Schiemann reaction: Balz, G.; Schiemann, G. Über aromatische Fluorverbindungen, I.: Ein neues Verfahren zu ihrer Darstellung. Ber. Dtsch. Chem. Ges. B 1927, 60, 1186-1190.; Halex process: Finger, G. C.; Kruse, C. W. Aromatic Fluorine Compounds. VII. Replacement of Aromatic $-\mathrm{Cl}$ and $-\mathrm{NO}_{2}$ Groups by $-\mathrm{F}^{1,2}$. J. Am. Chem. Soc. 1956, 78, 6034-6037.

(6) (a) Wang, X.; Mei, T.-S.; Yu, J.-Q. Versatile $\mathrm{Pd}(\mathrm{OTf})_{2} \cdot 2 \mathrm{H}_{2} \mathrm{O}$-Catalyzed ortho-Fluorination Using NMP as a Promoter. J. Am. Chem. Soc. 2009, 131, 7520-7521. (b) Mazzotti, A. R.; Campbell, M. G.; Tang, P.; Murphy, J. M.; Ritter, T. Palladium(III)-Catalyzed Fluorination of Arylboronic Acid Derivatives. J. Am. Chem. Soc. 2013, 135, 14012-14015. (c) Hull, K. L.; Anani, W. Q.; Sanford, M. S. Palladium-Catalyzed Fluorination of Carbon-Hydrogen Bonds. J. Am. Chem. Soc. 2006, 128, 7134-7135. (d) Chan, K. S. L.; Wasa, M.; Wang, X.; Yu, J.-Q. Palladium(II)-Catalyzed Selective Monofluorination of Benzoic Acids Using a Practical Auxiliary: A Weak-Coordination Approach. Angew. Chem., Int. Ed. 2011, 50, 9081-9084. (e) PeŕezTemprano, M. H.; Racowski, J. M.; Kampf, J. W.; Sanford, M. S. Competition Between sp ${ }^{3}-\mathrm{C}-\mathrm{N}$ vs $\mathrm{sp}^{3} \mathrm{C}-\mathrm{F}$ Reductive Elimination from Pd ${ }^{\mathrm{IV}}$ Complexes. J. Am. Chem. Soc. 2014, 136, 40974100. (f) Ball, N. D.; Sanford, M. S. Synthesis and Reactivity of a Mono- $\sigma-A r y l$ Palladium(IV) Fluoride Complex. J. Am. Chem. Soc. 2009, 131, 3796-3797. (g) Furuya, T.; Benitez, D.; 
Tkatchouk, E.; Strom, A. E.; Tang, P.; Goddard, W. A.; Ritter, T. Mechanism of C-F Reductive Elimination from Palladium(IV) Fluorides. J. Am. Chem. Soc. 2010, 132, 3793-3807. (h) Ding, Q.; Ye, C.; Pu, S.; Cao, B. Pd( $\left.\mathrm{PPh}_{3}\right)_{4}$-Catalyzed Direct ortho-Fluorination of 2-Arylbenzothiazoles with an Electrophilic Fluoride $N$-Fluorobenzenesulfonimide (NFSI). Tetrahedron 2014, 70, 409416. (i) Lou, S.-J.; Xu, D.-Q.; Xia, A.- B.; Wang, Y.-F.; Liu, Y.-K.; Du, X.-H.; Xu, Z.-Y. $\mathrm{Pd}(\mathrm{OAc})_{2}$-Catalyzed Regioselective Aromatic $\mathrm{C}-\mathrm{H}$ Bond Fluorination. Chem. Commun. 2013, 49, 6218-6220.

(7) (a) Grushin, V. V. The Organometallic Fluorine Chemistry of Palladium and Rhodium: Studies toward Aromatic Fluorination. Acc. Chem. Res. 2010, 43, 160-171. (b) Grushin, V. V.; Marshall, W. J. Ar-F Reductive Elimination from Palladium(II) Revisited. Organometallics 2007, 26, 49975002. (c) Grushin, V. V. Palladium Fluoride Complexes: One More Step toward Metal Mediated C-F Bond Formation. Chem. -Eur. J. 2002, 8, 1006-1014. (d) Yandulov, D. V.; Tran, N. T. ArylFluoride Reductive Elimination from Pd(II): Feasibility Assessment from Theory and Experiment. J. Am. Chem. Soc. 2007, 129, 1342-1358.

(8) (a) Watson, D. A.; Su, M.; Teverovskiy, G.; Zhang, Y.; Garcia-Fortanet, J.; Kinzel, T.; Buchwald, S. L. Formation of ArF from LPdAr(F): Catalytic Conversion of Aryl Triflates to Aryl Fluorides. Science, 2009, 325, 1661-1664. (b) Sather, A. C.; Buchwald, S. L. The Evolution of $\mathrm{Pd}^{0} / \mathrm{Pd}^{\mathrm{II}}$-Catalyzed Aromatic Fluorination. Acc. Chem. Res. 2016, 49, 2146-2157. (c) Lee, H. G.; Milner, P. J.; Buchwald, S. L. An Improved Catalyst System for the Pd-Catalyzed Fluorination of (Hetero)Aryl Triflates. Org. Lett. 2013, 15, 5602-5605. (d) Lee, H. G.; Milner, P. J.; Buchwald, S. L. Pd-Catalyzed Nucleophilic Fluorination of Aryl Bromides. J. Am. Chem. Soc. 2014, 136, 3792-3795. (e) Sather, A. C.; Lee, H. G.; De La Rosa, V. Y.; Yang, Y.; Müller, P.; Buchwald, S. L. A Fluorinated Ligand Enables Room-Temperature and Regioselective Pd-Catalyzed Fluorination of Aryl Triflates and Bromides. J. Am. Chem. Soc. 2015, 137, 13433-13438. (f) Milner, P. J.; Yang, Y.; Buchwald, S. L. In-Depth Assessment of the Palladium-Catalyzed Fluorination of Five-Membered Heteroaryl Bromides. Organometallics 2015, 34, 4775-4780.

(9) (a) Maimone, T. J.; Milner, P. J.; Kinzel, T.; Zhang, Y.; Takase, M. K.; Buchwald, S. L. Evidence for in Situ Catalyst Modification during the Pd-Catalyzed Conversion of Aryl Triflates to Aryl Fluorides. J. Am. Chem. Soc. 2011, 133, 18106-18109. (b) Milner, P. J.; Maimone, T. J.; Su, M.; Chen, J.; Müller, P.; Buchwald, S. L. Investigating the Dearomative Rearrangement of Biaryl Phosphine-Ligated Pd(II) Complexes. J. Am. Chem. Soc. 2012, 134, 19922-19934. (c) Milner, P. J.; Kinzel, T.; Zhang, Y.; Buchwald, S. L. Studying Regioisomer Formation in the Pd- 
Catalyzed Fluorination of Aryl Triflates by Deuterium Labeling. J. Am. Chem. Soc. 2014, 136, $15757-15766$.

(10) For reviews, see: (a) Purser, S.; Moore, P. R.; Swallow, S.; Gouverneur, V. Fluorine in Medicinal Chemistry. Chem. Soc. Rev. 2008, 37, 320-330. (b) Neumann, C. N.; Ritter, T. LateStage Fluorination: Fancy Novelty or Useful Tool. Angew. Chem. Int. Ed. 2015, 54, 3216-3221. (c) Kirk, K. L. Fluorination in Medicinal Chemistry: Methods, Strategies, and Recent Developments. Org. Process Res. Dev. 2008, 12, 305-321. (d) Müller, K.; Faeh, C.; Diederich, F. Fluorine in Pharmaceuticals: Looking Beyond Intuition. Science 2007, 317, 1881-1886. [iَpepi

(11) (a) Welch, J.; Lin, J. Fluoroolefin Containing Dipeptide Isosteres as Inhibitors of Dipeptidyl Peptidase IV(CD26). Tetrahedron 1996, 52, 291-304. (b) Narumi, T.; Hayashi, R.; Tomita, K.; Kobayashi, K.; Tanahara, N.; Ohno, H.; Naito, T.; Kodama, E.; Matsuoka, M.; Oishi, S.; Fujii, N. Synthesis and Biological Evaluation of Selective CXCR4 Antagonists Containing Alkene Dipeptide Isosteres. Org. Biomol. Chem. 2010, 8, 616-621. (c) Lamy, C.; Hofmann, J.; ParrotLopez, H.; Goekjian, P. Synthesis of a Fluoroalkene Peptidomimetic Precursor of N-Acetyl-1Glutamyl-1-Alanine. Tetrahedron Lett. 2007, 48, 6177-6180. (d) Niida, A.; Tomita, K.; Mizumono, M.; Tanigaki, H.; Terada, T.; Oishi, S.; Otaka, A.; Inui, K.-I.; Fuji, N. Unequivocal Synthesis of (Z)-Alkene and (E)-Fluoroalkene Dipeptide Isosteres to Probe Structural Requirements of the Peptide Transporter PEPT1. Org. Lett. 2006, 8, 613-616. (e) Niida, A.; Mizumoto, M.; Narumi, T.; Inokuchi, E.; Oishi, S.; Ohno, H.; Otaka, A.; Kitaura, K.; Fujii, N. Synthesis of $(Z)$-Alkene and $(E)$-Fluoroalkene-Containing Diketopiperazine Mimetics Utilizing Organocopper-Mediated Reduction-Alkylation and Diastereoselectivity Examination Using DFT Calculations. J. Org. Chem. 2006, 71, 4118-4129.

(12) Ye, Y.; Takada, T.; Buchwald, S. L. Palladium-Catalyzed Fluorination of Cyclic Vinyl Triflates: Effect of $\mathrm{TESCF}_{3}$ as an Additive. Angew. Chem., Int. Ed. 2016, 55, 15559-15563.

(13) When L2Pd(vinyl)Br (C1) was treated with AgF, fluorinated products were formed (see Scheme 4). However, no products were observed in the presence of $\mathrm{TESCF}_{3}$.

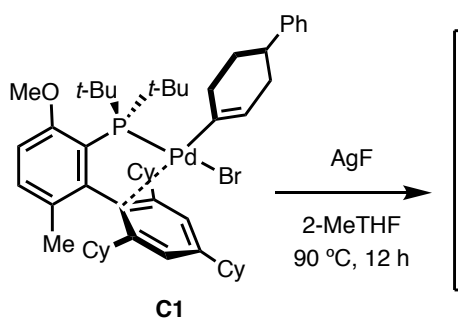

C1

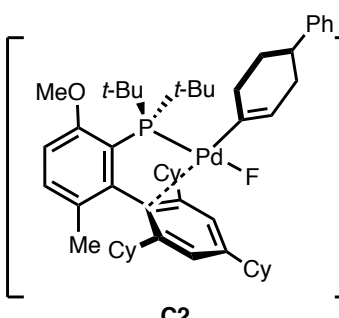

C2

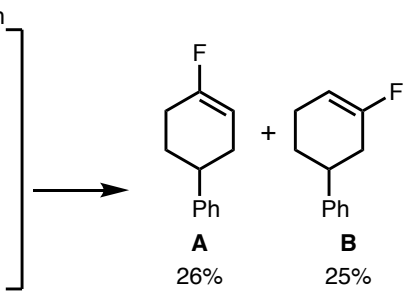

$\mathbf{A}: \mathbf{B}=1: 1$

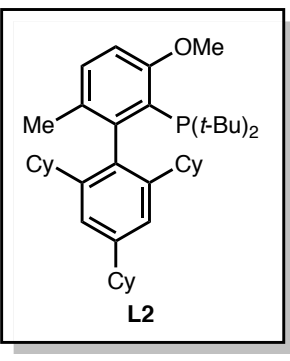



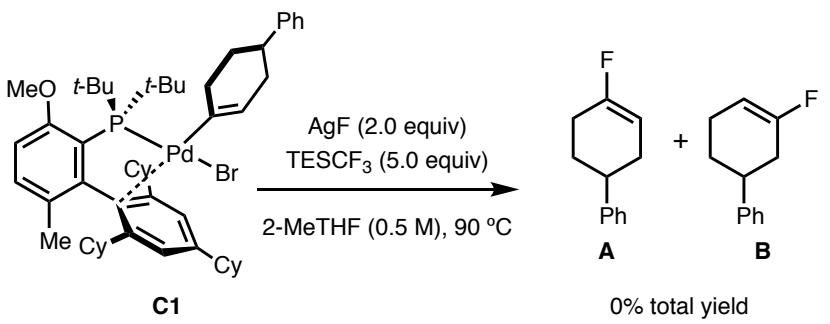

(14) (a) Zhao, Y.; Truhlar, D. G. The M06 Suite of Density Functionals for Main Group Thermochemistry, Thermochemical Kinetics, Noncovalent Interactions, Excited States, and Transition Elements: Two New Functionals and Systematic Testing of Four M06-Class Functionals and 12 Other Functionals. Theor. Chem. Acc. 2008, 120, 215-241. (b) Ditchfield, R.; Hehre, W. J.; Pople, J. A. Self-Consistent Molecular-Orbital Methods. IX. An Extended GaussianType Basis for Molecular-Orbital Studies of Organic Molecules. J. Chem. Phys. 1971, 54, 724 728. (c) Hay, P. J.; Wadt, W. R. Ab initio Effective Core Potentials for Molecular Calculations. Potentials for the Transition Metal Atoms Sc to Hg. J. Chem. Phys. 1985, 82, 270-283. (d) Wadt, W. R.; Hay, P. J. Ab initio Effective Core Potentials for Molecular Calculations. Potentials for Main Group Elements Na to Bi. J. Chem. Phys. 1985, 82, 284-298. (e) Hay, P. J.; Wadt, W. R. Ab initio Effective Core Potentials for Molecular Calculations. Potentials for $\mathrm{K}$ to Au Including the Outermost Core. J. Chem. Phys. 1985, 82, 299-310. (f) Dunning, T. H., Jr. Gaussian Basis Sets for Use in Correlated Molecular Calculations. I. The Atoms Boron Through Neon and Hydrogen. $J$. Chem. Phys. 1989, 90, 1007-1023.

(15) Liu, X.; Xu, C.; Wang, M.; Liu, Q. Trifluoromethyltrimethylsilane: Nucleophilic Trifluoromethylation and Beyond. Chem. Rev. 2015, 115, 683-730. (16) Prakash, G. K. S.; Wang, F.; Zhang, Z.; Haiges, R.; Rahm, M.; Christe, K. O.; Mathew, T.; Olah, G. A. Long-Lived Trifluoromethanide Anion: A Key Intermediate in Nucleophilic Trifluoromethylations. Angew. Chem. Int. Ed. 2014, 53, 11575-11578.

(17) Lishchynskyi, A.; Miloserdov, F. M.; Martin, E.; Benet-Buchholz, J.; Escudero-Adán, E. C.; Konovalov, A. I.; Grushin, V. V. The Trifluoromethyl Anion. Angew. Chem. Int. Ed. 2015, 54, 15289-15293.

(18) Cho, E. J.; Buchwald, S. L. The Palladium-Catalyzed Trifluoromethylation of Vinyl Sulfonates. Org. Lett. 2011, 13, 6552-6555.

(19) Ueda, S.; Ali, S.; Fors, B. P.; Buchwald, S. L. $\mathrm{Me}_{3}(\mathrm{OMe}) t$ BuXPhos: A Surrogate Ligand for $\mathrm{Me}_{4} t \mathrm{BuXPhos}$ in Palladium-Catalyzed $\mathrm{C}-\mathrm{N}$ and $\mathrm{C}-\mathrm{O}$ Bond-Forming Reactions. J. Org. Chem. 2012, 77, 2543-2547. 
(20) (a) Our attempts to prepare $\mathbf{L} 2 \mathrm{Pd}\left(\right.$ vinyl) $\mathrm{CF}_{3}$ from either $\mathbf{L} 2 \mathrm{Pd}$ (vinyl) $\mathrm{Br}$ or $\mathbf{L} 2 \mathrm{Pd}$ (vinyl)OTf all provided $<5 \%$ of $\mathbf{L} 2 \mathrm{Pd}$ (vinyl) $\mathrm{CF}_{3}$, as observed by ${ }^{19} \mathrm{~F}$ NMR analysis of the crude reaction mixture. (b) Pu, M.; Sanhueza, I. A.; Senol, E.; Schoenebeck, F. Divergent Reactivity of Stannane and Silane in the Trifluoromethylation of Pd ${ }^{\mathrm{II}}$ : Cyclic Transtion State versus Difluorocarbene Release. Angew. Chem. Int. Ed. 2018, 57, 15081-15085. (c) Cho, E. J.; Senecal, T. D.; Kinzel, T.; Zhang, Y.; Watson, D. A.; Buchwald, S. L. The Palladium-Catalyzed Trifluoromethylation of Aryl Chlorides. Science 2010, 328, 1679-1681.

(21) (a) Allgeier, A. M.; Shaw, B. J.; Hwang, T.-L.; Milne, J. E.; Tedrow, J. S.; Wilde, C. N. Characterization of Two Stable Degradants of Palladium $t$ BuXPhos Catalyst and a Unique Dearomatization Reaction. Organometallics 2012, 31, 519-522. (b) Lee, H. G.; Milner, P. J.; Colvin, M. T.; Andreas, L.; Buchwald, S. L. Structure and Reactivity of [(LPd $)_{\mathrm{n}}(1,5-$ cyclooctadiene)] ( $\mathrm{n}=1-2)$ Complexes Bearing Biaryl Phosphine Ligands. Inorganic Chimica Acta, 2014, 422, 188-192. (c) Lee, H. G.; Milner, P. J.; Buchwald, S. L. An Improved Catalyst System for the Pd-Catalyzed Fluorination of (Hetero)Aryl Triflates. Org. Lett. 2013, 15, 5602-5605.

(22) Based on calculations, attacking by $\mathrm{CF}_{3}{ }^{-}$has a lower energy barrier than by $\mathrm{CF}_{2}$ carbene (see the Supporting Information for details).

(23) The trifluoromethylative dearomatization of the bottom ring of $\mathbf{L} 1$ places a negative charge on the aryl component and turns the weakly coordinating, neutral, $\pi$-basic arene ligand into a stronger, anionic donor ligand. Accordingly, the energy preference for the trans-isomer (transeffect) becomes insignificant and the computed electronic energies of the two isomers become equal. The preference for the cis-isomer is therefore governed by solvation energy (see the Supporting Information for details). 